\title{
An application of a fixed point theorem in cone metric spaces for solving differential equations
}

\section{Monica Lauran and ANdrei Horvat-MarC}

\section{ABSTRACT.}

In this paper we establish sufficient conditions for the existence and uniqueness of solutions for third order differential equations using a fixed point theorem in cone metric space. The presented result is based on some properties of invertible operators and extends several well-known comparable results in the literature.

\section{REFERENCES}

[1] Aage, C. T. and Salunke, J. N., On common fixed points for contractive type mappings in cone metric spaces, Bulletin of Mathematical Analysis and Applications, 1 (2009), No. 3, 10-15

[2] Banas, J. et al., Solutions of a functional integral equation in BC(R+), International Mathematical Forum, 1 (2006), No. 24, 1181-1194

[3] Beiranvand, A., Moradi, S., Omid, M. and Pazandeh, H., Two fixed point theorem for special mapping, arXiv:0903.1504v1 [math.FA]

[4] Berinde, V., Abstract $\varphi$-contractions which are Picard mappings, Mathematica, 34(57) (1992), No. 2, 107-111

[5] Edelstein, M., On fixed and periodic points under contractive mappings, J. London Math. Soc., 37 (1962), 74-79

[6] Huang, L.-G. and Zhang, X., Cone metric spaces and fixed point theorems of contractive mappings, J. Math. Anal. Appl., vol. 332, No. 2, 2007, $1468-1476$

[7] Kadelburg, Z., Radenović, S. and Rakočević, A note on the equivalence of some metric and cone metric fixed point results, Applied Mathematics Letters, 24 (2011), 370-374

[8] Morales, J. R. and Rojas, E., Cone metric spaces and fixed point theorems of T-contrative mappings, Notas de Matemtica, vol. 4(2), No. 269, 2008, 66-78

[9] Morales, J. R. and Rojas, E., Cone Metric Spaces and Fixed Point Theorems of T-Kannan Contractive Mappings, Int. Journal of Math. Analysis, Vol. 4, 2010, No. 4, 175-184

[10] Olaleru, J. O., Some generalizations of fixed point theorems in cone metric spaces, Fixed Point Theory Appl., 2009, 10 (2009). Article ID 657914

[11] Rezapour, Sh. and Hamlbarani, R., Some notes on the paper cone metric spaces and fixed point theorems of contractive mappings, J. Math. Anal. Appl., 345, 719724 (2008). doi:10.1016/j.jmaa.2008.04.049

[12] Şerban, M. A., A nonlinear mixed type Volterra-Fredholm functional integral equation via Perov's theorem, TJMM, 2 (2010), No. 1, 75-87

[13] Vetro, P., Common fixed points in cone metric spaces, Rend. Circ. Mat. Palermo., 56, 464-468 (2007). doi:10.1007/BF03032097

[14] Zabreiko, P. P., K-metric and K-normed spaces: survey, Collect Math., 48 (1997), 825-859

Department of Mathematics And COMPUter SCiEnCE

Faculty of SCIENCES North University CEnTER at Baia Mare

TECHNICAL UNIVERSITY OF CLUJ-NAPOCA

VICTORIEI 76, 430122 BAIA MARE, ROMANIA

E-mail address: lauranmonica@yahoo.com

E-mail address: andrei.horvatmarc@unbm.ro

Received: 15.07.2012; In revised form: 20.02.2013; Accepted: 23.02.2013

2010 Mathematics Subject Classification. 45B05, 45D05, 47H10.

Key words and phrases. Cone metric space, contraction principle, integro-differential equation. 